\title{
The Role of Perceived Stress and Self-Efficacy in Young People's Life Satisfaction: A Longitudinal Study
}

\author{
Kaspar Burger $\mathbb{D}^{1} \cdot$ Robin Samuel $^{2}$
}

Received: 19 August 2016 / Accepted: 26 October 2016 / Published online: 3 November 2016

(C) Springer Science+Business Media New York 2016

\begin{abstract}
Life satisfaction is an important indicator of successful development. However, adolescents' life satisfaction tends to be relatively unsteady, and environmental influences play a critical role in shaping life satisfaction among adolescents in the transition to young adulthood. Given the paramount importance that education plays in adolescents' lives, adolescents' life satisfaction may vary as a function of school-related stress experience. At the same time, coping resources may help reduce adverse effects of stress on life satisfaction. With this in mind, we examined whether, and to what extent, perceived stress in education and general self-efficacy (a resource that facilitates coping) affect the life satisfaction of adolescents in transition to young adulthood. We distinguished between baseline levels of stress and self-efficacy and within-person change in stress and self-efficacy to determine whether life satisfaction is sensitive to fluctuations in stress and self-efficacy when person-specific levels of stress and self-efficacy are taken into account. Estimating growth curve models on data from a panel study on the life trajectories of compulsory-school leavers ( $n=5126,55.3 \%$ female), we found that baseline levels of stress and self-efficacy, as well as within-person change in stress and self-efficacy, affected adolescents' life satisfaction. Moreover, our results showed that baseline self-efficacy mitigated the negative effect of baseline stress on life satisfaction. These findings improve our
\end{abstract}

Kaspar Burger

kaspar.burger@unige.ch

1 Centre interfacultaire en droits de l'enfant, Université de Genève (Valais Campus), Case postale 4176, 1950 Sion 4, Suisse

2 Unité de recherche INSIDE, Université du Luxembourg, 11, Porte des Sciences, 4366 Esch-sur-Alzette, Luxembourg understanding of two major psychological determinants of adolescents' life satisfaction and extend our knowledge of life satisfaction trajectories during the transition to young adulthood.

Keywords Life satisfaction • Perceived stress • Self-efficacy $\cdot$ Education $\cdot$ Multilevel $\cdot$ Longitudinal

\section{Introduction}

Numerous studies have examined life satisfaction and its correlates in adults, to such an extent that by now it is widely recognized as an important indicator of adults' wellbeing and successful development (Diener and Chan 2011; Luhmann et al. 2013). By contrast, less is known about young people's life satisfaction (Antaramian et al. 2008; Gilman and Huebner 2003). Their life satisfaction is particularly worthy of attention because during their transition to adulthood young people face many developmental and adjustment challenges, including in the self, in the family, and at school (Hampel and Petermann 2006; Lerner and Galambos 1998) —most of which can influence their life satisfaction. In this study, we analyze whether, and to what extent, young people's life satisfaction is sensitive to perceived stress in education and general self-efficacy, because education constitutes one of the main sources of stress among young people (Persike and Seiffge-Krenke 2012), whereas self-efficacy has been considered a major resource facilitating adolescents' coping.

A negative psychological response to school-related stressors may occur when demands exceed resources, that is, when personal resources are no longer able to address 
school-related tasks. Young people may feel that they are unable to cope with their school subjects, or generally have the impression of being out of their depth at school, consequently appraising their lives less favorably (Suldo et al. 2006). Yet, the negative effects of stress may be attenuated by individuals' self-efficacy, that is, beliefs about the capability to master new or challenging tasks, to perform a given behavior, or to exercise control over events (Bandura 1997, 2006; Pinquart et al. 2003). Young people who reported high levels of academic self-efficacy not only displayed less test anxiety at school (Nie et al. 2011) and better achievement outcomes (Burger and Walk 2016), but also evaluated their lives more positively than their peers with lower levels of self-efficacy (Suldo and Huebner 2006). From this perspective, it is a reasonable assumption that both perceived stress in education and self-efficacy will affect young people's life satisfaction.

Levels of stress and self-efficacy vary considerably between young people and, in particular during the transition to adulthood, they tend to change significantly within persons over time (Eicher et al. 2014; Pinquart et al. 2003). Accordingly, we expect that life satisfaction is affected not only by a person's average (baseline) levels of perceived stress and self-efficacy over time, but also by intraindividual change in perceived stress and self-efficacy over time. So far there is very little longitudinal evidence regarding the question of whether, and to what extent, life satisfaction is shaped by person-specific average levels of, and within-person change in, stress and self-efficacy. This is surprising given that it has been recognized for a while, for instance, that dispositional components of stress (e.g., chronic dissatisfaction) need to be considered separately in the analysis of influences of environmental strains and demands on individuals' stress reactions (e.g., Watson 1990). While a recent longitudinal study provided evidence of the positive impact of a personal psychological resource (optimism) and social resources (including perceived social support and peer relationships) on life satisfaction in early adolescence (Oberle et al. 2011), most studies investigating life satisfaction in adolescence and young adulthood use cross-sectional designs and are based on small-scale convenience samples (see also Huebner et al. 2012). While these studies have successfully explored various facets of young people's life satisfaction (Bradley and Corwyn 2004; Park 2005; Proctor et al. 2009), they could not provide robust estimations of the associations of person-specific levels of perceived stress and self-efficacy (i.e., average stress and self-efficacy over time) with life satisfaction, and were unable to explain the effects of fluctuating stress and self-efficacy.

Our study attempted to fill the research gap noted above by using a longitudinal design and a representative largescale sample of young people. We distinguished between baseline levels of stress and self-efficacy over time and intra-individual deviation from this baseline level in stress and self-efficacy at a given point in time. This allowed us to assess whether life satisfaction is sensitive to fluctuations in stress and self-efficacy over and above baseline levels of stress and self-efficacy over time. This distinction is important in light of theory whereby life satisfaction may change over time (Baird et al. 2010) and because adolescence and young adulthood is a period in life during which life satisfaction might react particularly strongly to changes in stress and self-efficacy (Buchanan and Hughes 2011; Moksnes et al. 2014; Sánchez-Álvarez et al. 2015).

\section{Life Satisfaction in Young People}

Life satisfaction features prominently in a growing body of literature in the social sciences in relation to the psychological and social consequences of educational experiences (Keller et al. 2014; Lewis et al. 2011; Tolan and Larsen 2014). Life satisfaction is an expression of how an individual judges the quality of his or her life. As such, it is not simply an auxiliary effect of positive life experiences, but a meaningful indicator of well-being (Huebner et al. 2006). Life satisfaction reflects a sense of contentment and congruency between needs or wants and accomplishments (Keyes and Waterman 2003), and is conceptually and empirically distinguishable from positive and negative affect (McKnight et al. 2002).

An increasing number of studies suggest that life satisfaction is a predictor of various outcomes. For instance, high life satisfaction may bring about feelings of selfesteem (Proctor et al. 2009), better psychological adjustment (Peterson et al. 1998), and educational and occupational success (Lyubomirsky et al. 2005; Samuel et al. 2013). These findings suggest that life satisfaction plays an important role across the life course. However, although there is extensive research on adults' subjective evaluations of their lives (Diener 2009), young people's life satisfaction trajectories during the transition to adulthood are less wellunderstood (Salmela-Aro and Tynkkynen 2010). Huebner et al. (2012, p. 355) note that, compared to studies on adults' life satisfaction, research on youth life satisfaction "has lagged significantly behind," and that there is a lack of representative large-scale studies. Various experiences, such as stress at school, are specific to adolescence and young adulthood. Furthermore, in comparison to adult groups, life satisfaction among young people is unsteady (Lucas and Donnellan 2007). Thus, the question of whether, and to what extent, adolescents' life satisfaction trajectories are affected by perceived stress and self-efficacy takes on great importance in developmental research. 


\section{The Effects of Perceived Stress and Self-Efficacy on Young People's Life Satisfaction}

Against the backdrop of developmental challenges, including physical and emotional changes, stressful life events can affect adolescents' life satisfaction (Ash and Huebner 2001). In particular, research suggests that stressful life events explain variance in adolescents' life satisfaction over and above intrapersonal variables such as self-concept and internal locus of control (McCullough et al. 2000). However, the ways in which adolescents evaluate stressful life events can vary across individuals. Hence, rather than stressful events per se, perceived stress in a given situation must be considered. Among adolescents, perceived stress seems to be most pronounced in the domain of schooling (Persike and Seiffge-Krenke 2012). Considering the paramount importance that education and educational credentials have for young people's job prospects and life chances, perceived stress in school may also be associated with young people's general life satisfaction. Using a convenience sample of undergraduate college students, Chang (1998) did indeed find perceived stress to be negatively associated with life satisfaction. However, the cross-sectional nature of his study did not allow for measuring perceived stress and its effects on life satisfaction over time. Measuring the impact of within-person change in perceived stress on life satisfaction is crucial, particularly among young people who are likely to experience changing levels of stress over time (e.g., McNamara 2000). Prior research has emphasized the volatility of young people's perceived stress in education and suggested that even temporally limited increases in school-related stress can affect young people's educational trajectories (Eicher et al. 2014). However, the effects of fluctuations in perceived stress on life satisfaction are not well-understood. It is therefore important to analyze perceived stress in a longitudinal design and to distinguish person-specific baseline levels of perceived stress from within-person change in perceived stress.

In education, while some students may react with increased levels of stress when confronted with particular school demands, personal resources can influence their stress appraisal and attenuate the negative effects of stressors. ${ }^{1}$ The transactional model of stress and coping conceptualizes stress as an imbalance between environmental demand and an individual's response capability (Lazarus and Folkman 1984). In accordance with this model, we assume that personal resources reduce the adverse impact of perceived stress on life satisfaction. As noted above, self-efficacy may be a prime resource in this regard as it facilitates coping (Bandura 1997). High levels of self-efficacy are associated with goal setting, persistence, and a constructive way of dealing with failures (Schwarzer 2000). Furthermore,

\footnotetext{
${ }^{1}$ On the distinction between social resources (including social support and networks) and personal resources (including mental health, skills and personal traits), see, for instance, Hobfoll (2002).
}

self-efficacy enables individuals to trust their capabilities and to face stressful demands with confidence (Jerusalem and Mittag 1995). Hence, higher levels of self-efficacy are likely to weaken negative effects of stress on life satisfaction. To date, little empirical evidence exists regarding whether self-efficacy is associated with life satisfaction over time and whether selfefficacy actually reduces the adverse effects of perceived stress on young people's life satisfaction. In addition, we lack knowledge of the effects of within-person change in selfefficacy over time on young people's life satisfaction. Such knowledge would be essential as despite the fact that selfefficacy is often conceptualized as relatively stable across time (e.g., Scholz et al. 2002), research has shown that self-efficacy develops during adolescence (Caprara et al. 2011; Pajares and Urdan 2006) and that self-efficacy beliefs may change during and after transitions (e.g., Ainscough et al. 2016; Ouweneel et al. 2013; see also Yeo and Neal 2006).

\section{Study Purpose and Hypotheses}

The overall goal of our study was to examine young people's life satisfaction after the transition to post-compulsory education, using a representative sample in a longitudinal design over the course of four years. More specifically, we sought to address four gaps in the literature.

First, we intended to examine how baseline levels of perceived stress and self-efficacy over time affect young people's life satisfaction trajectories. Drawing on evidence of between-person variation in perceived stress (e.g., Mroczek and Almeida 2004) and perceived self-efficacy (Peng et al. 2015), we hypothesized that baseline stress over time is negatively associated with life satisfaction (Hypothesis 1) and that baseline self-efficacy over time is positively associated with life satisfaction (Hypothesis 2).

Second, we aimed to assess whether young people's life satisfaction is sensitive to yearly fluctuations in perceived stress and self-efficacy - that is, deviations in perceived stress and self-efficacy from their respective baseline levels-when controlling for baseline stress and self-efficacy. Given withinperson volatility in perceived stress (Eicher et al. 2014) and self-efficacy (Sitzmann and Yeo 2013) across time, examining temporal fluctuation in these characteristics in conjunction with their person-specific mean levels shall provide a more holistic perspective on their consequences for life satisfaction. We expected that an increase in perceived stress at a given point in time, relative to an individual's average stress level, would be negatively associated with life satisfaction (Hypothesis 3), while an increase in self-efficacy, relative to an individual's average level of self-efficacy, would be positively associated with life satisfaction (Hypothesis 4).

Our third aim was to analyze how baseline stress and self-efficacy interact in shaping young people's life 
Table 1 Number of respondents in different educational tracks from 2001 to 2004

\begin{tabular}{lclllll}
\hline & $\begin{array}{l}\text { Compulsory } \\
\text { school }\end{array}$ & $\begin{array}{l}\text { Vocational } \\
\text { education }\end{array}$ & & \multicolumn{2}{l}{ General education } & Total \\
\cline { 3 - 6 } & & $\begin{array}{l}\text { Academic } \\
\text { high } \\
\text { school }\end{array}$ & $\begin{array}{l}\text { University of } \\
\text { applied } \\
\text { sciences }\end{array}$ & University \\
\hline 2001 & 593 & 2746 & 1787 & 0 & 0 & 5126 \\
2002 & 23 & 2991 & 1630 & 0 & 0 & 4644 \\
2003 & 2 & 2750 & 1588 & 4 & 0 & 4344 \\
2004 & 2 & 1649 & 1155 & 89 & 252 & 3147 \\
\hline
\end{tabular}

Participants who were in education between 2001 and 2004 and who were included in our analyses; further participants (not included in this Table) were engaged in other (short-term) activities such as language courses, language stays, internships, preparation courses for apprenticeships or general education tracks; or were not in education, employment or training; or were employed satisfaction. Based on the transactional model of stress and coping (Lazarus and Folkman 1984), a few studies suggest that baseline stress and self-efficacy interactively influence life satisfaction (Hamarat et al. 2001; Schmeelk-Cone and Zimmerman 2003). According to this line of reasoning, the effects of school-related stress on life satisfaction may vary as a function of individuals' baseline levels of self-efficacy, a resource that facilitates coping. Hence we expected that baseline self-efficacy would moderate adverse effects of baseline stress on life satisfaction (Hypothesis 5).

Fourth, intra-individual change (fluctuation) in the levels of perceived stress and self-efficacy may interact with the corresponding baseline levels in shaping life satisfaction. We therefore hypothesized that within-person change in self-efficacy would moderate the effects of baseline stress on life satisfaction (Hypothesis 6), and that baseline levels of self-efficacy would moderate the effects of within-person change in perceived stress (Hypothesis 7). Moreover, we examined whether within-person change in self-efficacy and within-person change in stress interactively shape life satisfaction, but we did not derive and test a formal hypothesis given the lack of available evidence.

\section{Method}

\section{Sample}

The study drew on data from the Transitions from Education to Employment (TREE) project, the first panel study examining the post-compulsory educational and labor market trajectories of school leavers in Switzerland. ${ }^{2}$ The initial sample included 6343 young people who participated in the Program for International Student Assessment (PISA)

\footnotetext{
2 The Swiss youth panel study "TREE" has been running since 2000 and is mainly funded by the Swiss National Science Foundation (distribution: Data service, FORS, Lausanne).
}

in the year 2000 (Bergman et al. 2011). In this study, we used data from the first four waves (2001 to 2004), which cover the period when the participants transitioned from lower secondary education to upper secondary education (most participants were in their first year of upper secondary education in the first panel wave). We restricted the sample to participants who were either in a vocational education track or in a general education track, because our study focused on the influence of perceived stress in education on life satisfaction trajectories. This resulted in an analytical sample of 5126 participants in the first panel wave. Table 1 presents the number of participants in different educational tracks in each of the four panel waves. Compulsory school refers to lower secondary education, vocational education refers to professional training in an apprenticeship, and general education refers to educational tracks that lead to higher education. The analytical sample in wave 1 , relative to the initial sample in 2000 , included slightly more women (55.3 vs. $54.2 \%$ ), individuals born in Switzerland (88.4 vs. $85.7 \%$ ), individuals with a higher socio-economic status, as measured by the international socio-economic index of occupational status $(M=51.6$ vs. $M=50.4)$, and individuals with higher levels of school performance, as indicated by the PISA reading score $(M=524.5$ vs. $M=510.0)$. In 2000, when the PISA assessment took place, the mean age of the participants was 15.47 years $(\mathrm{SD}=0.63)$. Panel waves were conducted at annual intervals, hence participants were four years older in panel wave 4 . In the complete sample the response rates across panel waves were high, varying between 85 and 89 percent in each of the first four waves (TREE 2013). However, in our analytical sample, the number of participants decreased more rapidly, because the number of participants who were no longer in education increased between 2001 and 2004 (in Switzerland adolescents start to leave the education system as of age 17). Despite the high response rates, we did not have complete information on all relevant items across the four panel waves. Thus, as in any study with missing information, 
we had to adjust the estimation of parameters to the presence of missing data. We replaced missing values with imputed data by calculating maximum-likelihood estimates using the expectation-maximization algorithm, which enables parameter estimation in a probabilistic model with incomplete data (Dempster et al. 1977; Do and Batzoglou 2008).

\section{Measures}

Data were collected through standardized written questionnaires. Participants who did not return the questionnaire were contacted again and asked to take part in a telephone interview. In our models, we used socio-demographic data from the participants to eliminate potential confounding effects: gender $(0=$ female, $1=$ male $)$, immigrant background $(0=$ born in Switzerland, $1=$ born abroad $)$, and socio-economic status (measured by the socio-economic index of occupational status, which captures the position of occupations in the social stratification system and ranges from 16.00 to 90.00 ; with $M=51.62, \mathrm{SD}=16.25$; see Ganzeboom et al. 1992). We also included an indicator of participants' educational performance at age 15 (the PISA reading score; Adams and $\mathrm{Wu} 2002$ ) because educational performance may be related to perceived stress in education. Furthermore, the following variables were tested with participants in each panel wave:

\section{Educational Situation}

The educational situation was assessed using a dichotomous variable that distinguishes between the two main educational tracks that exist in Swiss upper secondary education, namely, vocational education and general education. Students attending a vocational track complete professional training for two to four years during which they typically enter the labor market as apprentices. Students in a general education track follow a program that prepares them for higher education, in particular university.

\section{Perceived Stress}

Perceived stress in the general education or vocational training context was assessed on a scale consisting of five items, adapted from a questionnaire on job analysis (Prümper et al. 1995). The scale ranged from 1 (very seldom/never) to 5 (very frequently/always). This scale was designed to capture the negative aspects of stress (as opposed to its more positive components; e.g., O'Sullivan 2010). The items were: "I have too much to do at school", "I am often unable to cope with my homework", "At school I often feel out of my depth", "The subjects of the lessons change so quickly that I struggle to follow", and "If I do not study during the weekends, I can hardly manage what is asked of me at school". Cronbach's alpha varied between .78 and .82 across the waves (t1: .78, $\mathrm{t} 2: .79, \mathrm{t} 3$ : $.79, \mathrm{t} 4: .82)$.

\section{Perceived Self-efficacy}

Perceived self-efficacy, also referred to as perceived general self-efficacy or general self-efficacy (Luszczynska et al. 2005; Schwarzer et al. 1999), was measured on a scale consisting of four items, adapted from Schwarzer and Jerusalem (1999) and Schwarzer (2000). The scale ranged from 1 (completely wrong) to 4 (completely right). The items were: "When a problem arises, I can always find a solution by my own efforts", "whatever happens, I will handle any difficult situation", "I am confident that I can cope with difficult challenges because I can trust my abilities", and "I can find a solution to any problem". Cronbach's alpha varied between .73 and .75 across the waves (t1: .75, t2: .73, t3: .74, t4: .74).

\section{Life Satisfaction}

The dependent variable-life satisfaction-was assessed on a scale consisting of five items (Grob et al. 1991), ranging from 1 (completely wrong) to 6 (completely right). The items were: "My future looks promising", "I am happy to live", "I am happy with the way my life plan is unfolding", "Whatever happens, I can see the bright side of it", and "My life seems meaningful to me". Cronbach's alpha varied between .83 and .85 across the waves ( $\mathrm{t} 1: .83, \mathrm{t} 2: .85, \mathrm{t} 3$ : $.85, \mathrm{t} 4: .85)$.

It could be argued that "perceived stress", "perceived selfefficacy", and "life satisfaction" are closely related and conceptually overlapping constructs. However, they are distinct both analytically and empirically. Analytically, life satisfaction is conceptualized as a result of a cognitive evaluation of one's life, whereas stress results from an imbalance between demands and an individual's resources, and self-efficacy relates to an individual's belief about the capacity to master a given task. Empirically, the correlation between the time-averaged values over four panel waves of perceived stress and life satisfaction was negative, but its strength was relatively weak $(r=-0.31)$. The correlation between perceived stress and perceived self-efficacy was negative, but also relatively weak $(r=-0.37)$. Finally, the correlation between perceived self-efficacy and life satisfaction was positive $(r=$ 0.55), suggesting that the relationship between these two constructs was stronger than that between the other constructs. 


\section{Data Analysis}

To examine the effects of baseline stress and self-efficacy over time, as well as the effects of fluctuation (change) in both, we fitted growth curve models within a multilevel modeling framework (e.g., Curran et al. 2010; Raudenbush and Bryk 2002), with measurement points (level 1) nested within individuals (level 2). These models let us identify a unique intercept and slope (or growth rate) in life satisfaction for each person. We were explicitly assuming variation in individual trajectories to support our aim of contributing to a better understanding of life satisfaction trajectories (Salmela-Aro and Tynkkynen 2010). All our continuous level-2 variables (i.e., baseline stress, baseline self-efficacy, SES, and reading score) were centered at the grand mean. We used maximum likelihood estimation with cluster and heteroskedasticity robust standard errors (Snijders and Bosker 2012). While not affecting the actual parameter estimates, these standard errors account for the fact that the measurements within persons will be correlated across time (Huber 1967; Rogers 1994). In our multilevel models, we used maximum-likelihood estimation, which is widely regarded to provide robust estimations if the assumed model is accurate, and, moreover, allows for comparing the fit of different models through likelihood ratio tests (Muthén and Shedden 1999; Schafer and Graham 2002).

We included our key variables, perceived stress and selfefficacy, at level 2 and level 1 in our models. At level 2, we included time-invariant measures of the baseline levels of perceived stress and self-efficacy. They are each calculated as the mean of the perceived stress and self-efficacy scales over the observational period of four years. At level 1, we included time-varying measures using person-meancentered variables ("change in stress" and "change in selfefficacy"). We used time-varying measures to assess intraindividual deviations in stress and self-efficacy in a given panel wave from the baseline levels of stress and selfefficacy. This approach is illustrated in the following example: Participants P1 and P2 display the same stress score of 2 in the year 2002. Across the four years, participant $\mathrm{P} 1$ reports an average level stress score of 3, whereas participant P2 reports an average level stress score of 2, with all scores here relating to the "baseline stress" values. The "change in stress" score of participant P1 in the year 2002 is -1 (or 2-3), whereas for participant P2 it is 0 (or 2-2). Thus, in 2002, participant P1 perceives a decrease in stress relative to his or her average stress level, whereas participant P2 perceives no change to individual-level stress (baseline stress). We distinguished between "baseline effect" and "change effect" to examine to what extent life satisfaction is affected by stable personal characteristics and/or by within-person change in the corresponding characteristic. Distinguishing between "baseline effect" and "change effect" was warranted because there was considerable fluctuation over time in perceived stress and in perceived selfefficacy: 63.4 percent of the variance in perceived stress was within persons (36.6\% was between persons); 63.6 percent of the variance in perceived self-efficacy was within persons (36.4\% was between persons) - as determined in unconditional multilevel models with perceived stress and perceived self-efficacy as dependent variables.

Our design allowed us to examine the hypotheses set out in the "study purpose and hypotheses" section. We estimated four multilevel models. In the first, unconditional model, we included only the dependent variable "life satisfaction". This allowed us to distinguish between within- and betweenperson variances in life satisfaction. In the second model, we included time as fixed and random effects, as well as all the time-invariant variables at level 2 , including baseline stress and baseline self-efficacy. In the third model, we added the time-varying variables "change in stress" and "change in self-efficacy" at level 1. In the fourth model, we included the interaction terms between stress and selfefficacy at both the between-person and within-person levels (level 2 and level 1). ${ }^{3}$

\section{Results}

Across the four waves, on average, perceived life satisfaction was relatively high, perceived stress was moderate, and perceived self-efficacy was moderate to relatively high (see Table 2). The between-wave correlations in the three variables were moderate to strong. They indicate within-person variation in life satisfaction, perceived stress, and selfefficacy over time. The correlations tended to be higher between measurement points that were close to each other. The correlations between stress and self-efficacy ranged from $r=-0.18$ to $r=-0.30$ across the four waves.

Table 3 summarizes the results of our multilevel models. The unconditional model (model 0 ), where no covariates are included, partitions the variance in the dependent variable "life satisfaction" into two components-within- and between-person variance. That is, this model allows us to

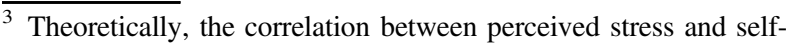
efficacy could constitute a multicollinearity problem in multivariate analyses with life satisfaction as the outcome variable. However, we calculated variance inflation factor (VIF) scores for baseline stress, baseline self-efficacy, change in stress, and change in self-efficacy, which turned out to be $1.24,1.20,1.03$, and 1.04. By even the most conservative standards, this does not indicate a problem, even more so as we ran our analyses on a comparably large sample. Even if there were a problem with multicollinearity, it would be associated with inflated standard errors and erroneous $p$-values, which would lead us to mistakenly not reject the null-hypothesis on the related coefficients. In other words, we would run the risk of not detecting statistically significant effects.
} 
Table 2 Descriptive statistics (means and standard deviations) and correlations between the central variables for panel waves 1 to 4

\begin{tabular}{lllll}
\hline & & $\begin{array}{l}\text { Life satisfaction } \\
\text { (Min: 1, Max: 6) }\end{array}$ & $\begin{array}{l}\text { Perceived stress } \\
\text { (Min: 1, Max: 5) }\end{array}$ & $\begin{array}{l}\text { Self-efficacy } \\
\text { (Min: 1, Max: 4) }\end{array}$ \\
\hline$M(\mathrm{SD})$ & $\mathrm{t} 1$ & $4.75(0.80)$ & $2.35(0.73)$ & $3.04(0.46)$ \\
$M(\mathrm{SD})$ & $\mathrm{t} 2$ & $4.74(0.72)$ & $2.36(0.64)$ & $2.98(0.43)$ \\
$M(\mathrm{SD})$ & $\mathrm{t} 3$ & $4.76(0.74)$ & $2.39(0.64)$ & $2.96(0.43)$ \\
$M(\mathrm{SD})$ & $\mathrm{t} 4$ & $4.74(0.78)$ & $2.39(0.72)$ & $3.02(0.46)$ \\
$r$ & $\mathrm{t} 1-\mathrm{t} 2$ & $0.63^{* * *}$ & $0.56^{* * *}$ & $0.56^{* * *}$ \\
$r$ & $\mathrm{t} 2-\mathrm{t} 3$ & $0.68^{* * *}$ & $0.68^{* * *}$ & $0.64 * * *$ \\
$r$ & $\mathrm{t} 3-\mathrm{t} 4$ & $0.71^{* * *}$ & $0.68^{* * *}$ & $0.65^{* * *}$ \\
$r$ & $\mathrm{t} 1-\mathrm{t} 3$ & $0.57 * * *$ & $0.51^{* * *}$ & $0.54 * * *$ \\
$r$ & $\mathrm{t} 2-\mathrm{t} 4$ & $0.62^{* * *}$ & $0.57^{* * *}$ & $0.57 * * *$ \\
$r$ & $\mathrm{t} 1-\mathrm{t} 4$ & $0.54 * * *$ & $0.41^{* * *}$ & $0.49^{* * *}$ \\
\hline
\end{tabular}

We tested longitudinal measurement invariance for our key research variables life satisfaction, perceived stress, and self-efficacy. All constructs exhibited configural invariance as well as excellent partial metric and partial scalar invariance over time, implying that any linear function of these constructs (i.e., person-specific averages and personmean-centered variables) and their items possess these properties as well

$* * * p<.001$

Table 3 Results from multilevel models predicting life satisfaction

\begin{tabular}{|c|c|c|c|c|c|c|c|c|}
\hline & \multicolumn{2}{|l|}{ Model 0} & \multicolumn{2}{|l|}{ Model 1} & \multicolumn{2}{|l|}{ Model 2} & \multicolumn{2}{|l|}{ Model 3} \\
\hline & $b$ & SE & $b$ & SE & $b$ & SE & $b$ & SE \\
\hline Time (linear) (1-1) & & & $-0.032 * *$ & 0.011 & 0.015 & 0.011 & 0.015 & 0.011 \\
\hline Time (quadratic) (1-1) & & & $0.012 * *$ & 0.004 & -0.002 & 0.003 & -0.002 & 0.003 \\
\hline Gender: male (1-2) & & & -0.020 & 0.015 & -0.020 & 0.015 & -0.018 & 0.015 \\
\hline Immigrant (1-2) & & & $-0.142 * * *$ & 0.025 & $-0.140 * * *$ & 0.024 & $-0.141 * * *$ & 0.024 \\
\hline Reading score (1-2) & & & -0.000 & 0.000 & -0.000 & 0.000 & -0.000 & 0.000 \\
\hline SES (1-2) & & & 0.001 & 0.000 & 0.001 & 0.000 & 0.001 & 0.000 \\
\hline General education track (1-1) & & & $0.045 * *$ & 0.015 & 0.024 & 0.015 & 0.027 & 0.015 \\
\hline Baseline stress (1-2) & & & $-0.153 * * *$ & 0.015 & $-0.157 * * *$ & 0.015 & $-0.724 * * *$ & 0.104 \\
\hline Baseline self-efficacy (1-2) & & & $0.848 * * *$ & 0.024 & $0.861 * * *$ & 0.024 & $0.402 * * *$ & 0.085 \\
\hline Change in stress (1-1) & & & & & $-0.118 * * *$ & 0.010 & $-0.276 * *$ & 0.088 \\
\hline Change in self-efficacy (1-1) & & & & & $0.428 * * *$ & 0.017 & $0.347 * * *$ & 0.068 \\
\hline Baseline stress $\times$ Baseline self-efficacy & & & & & & & $0.189 * * *$ & 0.034 \\
\hline Baseline stress $\times$ Change in self-efficacy & & & & & & & 0.033 & 0.028 \\
\hline Change in stress $\times$ Baseline self-efficacy & & & & & & & 0.052 & 0.029 \\
\hline Change in stress $\times$ Change in in self-efficacy & & & & & & & 0.019 & 0.040 \\
\hline Intercept & $4.744 * * *$ & 0.009 & $2.584 * * *$ & 0.091 & $2.536 * * *$ & 0.091 & $3.926 * * *$ & 0.267 \\
\hline Level 2 variance & 0.336 & 0.009 & 0.277 & 0.011 & 0.259 & 0.010 & 0.256 & 0.010 \\
\hline Level 1 variance & 0.218 & 0.004 & 0.186 & 0.004 & 0.172 & 0.004 & 0.172 & 0.004 \\
\hline Time variance (linear) & & & 0.022 & 0.002 & 0.016 & 0.002 & 0.016 & 0.002 \\
\hline Covariance (level 2 variance, time variance) & & & -0.035 & 0.004 & -0.024 & 0.004 & -0.024 & 0.004 \\
\hline Number of level 1 units & 17,272 & & 17,180 & & 17,180 & & 17,180 & \\
\hline Number of level 2 units & 5,638 & & 5,606 & & 5,606 & & 5,606 & \\
\hline-2 log likelihood & $32,313.9$ & & $29,953.1$ & & $28,689.9$ & & $28,645.4$ & \\
\hline
\end{tabular}

Unstandardized coefficients with cluster robust standard errors

The variables at level 1 (1-1) measure within-person effects, and the variables at level 2 (1-2) measure between-person effects $* p<.05, * * p<.01, * * * p<.001$ estimate the intra-class correlation (ICC), or the proportion of total variance between persons. The ICC suggests that $60.6 \%$ of the variance in life satisfaction was between persons, while $39.4 \%$ was within persons.

Model 1 includes time as fixed and random effects as well as all the time-invariant (level-2) variables. A key finding here is that individuals with above-average levels of baseline stress reported below-average levels of life satisfaction, while those with above-average levels of baseline self-efficacy indicated above-average satisfaction with their lives. Gender, reading score and SES had no significant effect on life satisfaction; however, immigrant status was associated with below-average levels of life satisfaction. By contrast, individuals in the general education track were, on average, more satisfied with their lives. This model further indicates both a negative linear effect and a positive quadratic effect of time, suggesting that life satisfaction declined over time, and that this negative trend slowed over time. The random effect of time at the person level (denoted as "time variance (linear)") was statistically significant, as indicated by a likelihood ratio test comparing the deviances 
of a model with a random effect of time, and of a reduced model without a random effect of time, $\chi^{2}(2)=218.3, p<$ 0.001 . This suggests that there were considerable betweenperson differences in the development of life satisfaction over time. Our model allowed the person-level random intercept ("level 2 variance") and the random slope of time at the person level ("time variance (linear)") to covary. This covariance between the variances was negative, which means that individuals with higher initial levels of life satisfaction showed a stronger decrease in life satisfaction over time and, conversely, the lower the initial levels of life satisfaction were, the less individuals' life satisfaction decreased over time.

In model 2 we added the time-varying variables "change in stress" and "change in self-efficacy," or, in other terms, we added stress and self-efficacy at level 1 . This model, extending the first, suggests that change in stress and change in self-efficacy significantly affected life satisfaction over and above baseline stress and baseline self-efficacy over time. Individuals who experienced less stress than usual, or perceived greater self-efficacy than usual, were likely to feel more satisfied with their lives, regardless of their baseline levels of stress and self-efficacy. This is further confirmed by a significantly better log-likelihood index of model 2 relative to model $1, \chi^{2}(2)=1263.2, p<0.001$. We note, moreover, that this model revealed no significant linear or quadratic time effects. Thus, while the ICC indicated that there was within-person variation in life satisfaction over time, with model 1 indicating a negative overall trend of life satisfaction over time, the average level of life satisfaction across participants seemed to remain stable across the four measurement points when the effects of change in stress and change in self-efficacy were taken into account.

In model 3, we included interaction terms between stress and self-efficacy at both the between-person and withinperson level, which significantly improved the model fit, $\chi^{2}(4)=44.5, p<0.001$. This model confirms the results of model 2 and provides further evidence for the following main effects of our key variables: on average, a one-unit (or 1.46 SD) increase in baseline stress was associated with a 0.724 units (or $0.95 \mathrm{SD}$ ) decrease in life satisfaction, a oneunit (2.26 SD) increase in baseline self-efficacy was associated with a 0.402 units $(0.91 \mathrm{SD})$ increase in life satisfaction, a one-unit (1.46 SD) increase in change in stress was associated with a 0.276 units $(0.37 \mathrm{SD})$ decrease in life satisfaction, and a one-unit (2.26 SD) increase in change in self-efficacy was associated with a 0.347 units (0.46 SD) increase in life satisfaction. In addition, model 3 indicates that the negative effect of baseline stress on life satisfaction was moderated by higher levels of baseline self-efficacy (as discussed further below). By contrast, the non-significant interactions indicate that change in the level of self-efficacy

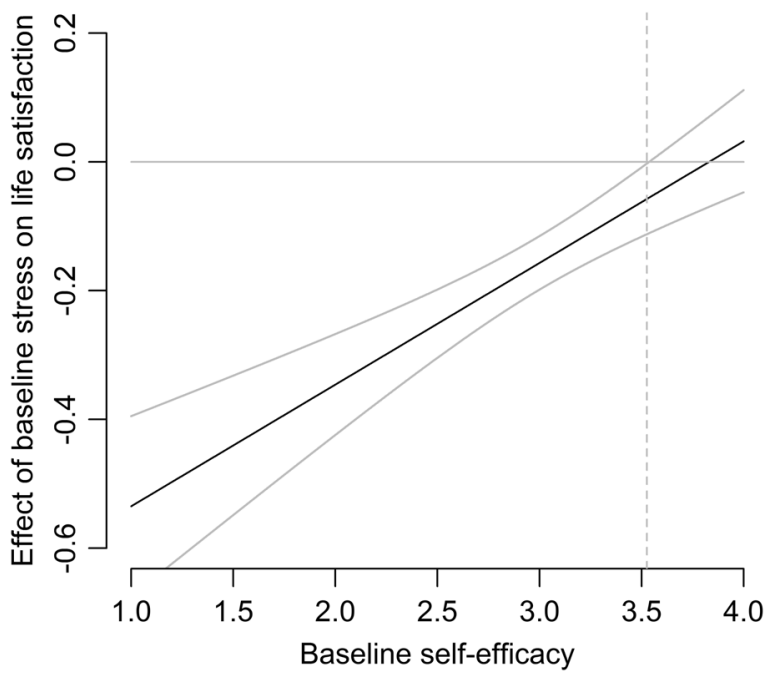

Fig. 1 Marginal effect of a one-unit increase in baseline stress on life satisfaction across the range of values of baseline self-efficacy

did not moderate the effects of baseline stress or of change in stress on life satisfaction, nor did baseline self-efficacy moderate the effect of change in stress on life satisfaction.

Out of four interaction terms tested in the final model, one interaction term was significant. To facilitate the interpretation of this significant interaction between baseline stress and baseline self-efficacy, we plotted the interaction in Fig. 1. This figure shows how the marginal effect of baseline stress on life satisfaction (y-axis) changes as a function of baseline self-efficacy ( $\mathrm{x}$-axis). The solid black line represents the effect of a one-unit increase in baseline stress across the range of baseline self-efficacy values when all other variables are kept at zero-or, for continuous variables, when they are at their grand or person mean. The $95 \%$ confidence interval is plotted in gray. Figure 1 indicates that a one-unit increase in baseline stress (or a 1.47 $\mathrm{SD}$ ) led to a decrease in life satisfaction by approximately 0.53 points (or a $0.71 \mathrm{SD}$ ) among individuals with low baseline self-efficacy (self-efficacy score of 1.0, left end of the $\mathrm{x}$-axis). By contrast, the effect of an increase in baseline stress on life satisfaction was no longer significant when baseline self-efficacy reached a value equal to, or greater than, 3.53, which corresponds to a 1.22 SD above the sample mean. ${ }^{4}$ In this case, the confidence interval includes the value of zero, as indicated by the vertical dashed line.

To assess the robustness of our findings, we ran model 2 and added the interaction terms one by one in separate models. This did not yield different results than those reported in Table 3. Furthermore, we included a random

\footnotetext{
${ }^{4}$ The sample mean of baseline self-efficacy is 2.99 points. A baseline self-efficacy level of 3.53 points deviates from the sample mean by 0.54 points. Given that 0.442 points correspond to 1 standard deviation, 0.54 points equal a 1.22 standard deviation.
} 
quadratic effect of time in our final model to assess whether between-person differences in the curvilinearity of life satisfaction trajectories could be identified. This did not change our findings and did not alter the model fit significantly, as indicated by a likelihood ratio test, $\chi^{2}(3)=$ $7.35, p=0.062$.

\section{Discussion}

The life satisfaction of adolescents in transition to young adulthood tends to be sensitive to environmental influences as adolescents face many developmental and adjustment challenges, for example, at school (Caprara et al. 2005; Moksnes et al. 2014; Sánchez-Álvarez et al. 2015). Connected to this, the realm of education has been described as a main source of stress for adolescents (Persike and SeiffgeKrenke 2012). While a few studies have analyzed several facets of early, middle, and late adolescents' life satisfaction (Oberle et al. 2011; Salmela-Aro and Tynkkynen 2010), the question of whether, and to what extent, life satisfaction is shaped by person-specific average (baseline) levels of, and within-person change across time in, school-related stress has not yet been addressed. Building on theory and recent research about the role of environmental demands and personal resources in shaping stress (see e.g., Peng et al. 2015), this study investigated whether, and in what way, perceived school-related stress and self-efficacy impact young people's life satisfaction during the transition to adulthood, using a longitudinal design and data from a representative sample of young people in Switzerland. An important assumption of our analyses was that there is individual variation in life satisfaction trajectories. We modelled this within a multilevel modeling framework where we specified a unique intercept and slope for each person's life satisfaction. Our models did indeed reveal considerable variation between young people's life satisfaction trajectories over time, which supports previous findings by Salmela-Aro and Tynkkynen 2010. Moreover, the use of a longitudinal design allowed us not only to study variation in life satisfaction trajectories, but also to estimate robust effects on life satisfaction of baseline levels of stress and self-efficacy over time. This was further enhanced by the application of a scale specifically designed to capture perceived stress in the domain of schooling.

Our first aim was to examine whether baseline levels of stress and self-efficacy (a resource that facilitates coping) affect life satisfaction over time (Hypotheses 1 and 2). As expected, baseline stress was negatively associated with life satisfaction, whereas baseline self-efficacy was positively associated with life satisfaction. Our findings are in line with evidence suggesting that, compared to perceived stress, self-efficacy might be a somewhat less important predictor of life satisfaction in young adults (Hamarat et al. 2001). More generally, this also supports the finding that "bad is stronger than good" (Baumeister et al. 2001), in that the experience of negative school-related stress has a stronger impact on young people's life satisfaction than self-efficacy, a resource that is instrumental in handling difficult situations and overcoming negative experiences.

Our second aim was to advance our understanding of the dynamic relationship between intra-individual change in perceived stress and self-efficacy, on the one hand, and life satisfaction on the other, thus contributing new evidence to the literature on young people's life satisfaction which is mainly built on cross-sectional studies (Huebner et al. 2012). The results corroborated the hypotheses that change in the levels of perceived stress and self-efficacy is associated with life satisfaction (Hypotheses 3 and 4). Increases in perceived stress relative to baseline stress over time were associated with a decrease in life satisfaction, and vice versa. Similarly, increases in self-efficacy were associated with an increase in life satisfaction, and vice versa. By highlighting that changes in the subjective experience of stress and self-efficacy affect life satisfaction, we contribute to literature emphasizing that affective states, over and above affective traits, impact individuals' cognitive appraisals (Eicher et al. 2014; Rosenberg 1998).

Thirdly, we examined the interplay between baseline stress and baseline self-efficacy. Our findings corroborated Hypothesis 5 that baseline self-efficacy moderates the negative effect of baseline stress on life satisfaction, thereby confirming the notion that it is not exclusively the experience of stress that may be harmful, but a combination of stress alongside a lack of resources to adequately cope (Grant et al. 2006). With increasing levels of baseline selfefficacy, the impact of baseline stress on life satisfaction weakened. High levels of self-efficacy even neutralized the adverse effects of baseline stress. Adding to research that relies on a transactional model of stress and considers the effects of young people's coping with stress on psychological adjustment (Compas et al. 2001) our analysis is one of the first to employ a longitudinal design to study the interaction between baseline stress and baseline selfefficacy as determinants of adolescents' life satisfaction. A particular advantage of our design was that it enabled robust time-averaged estimates of perceived stress and selfefficacy (baseline levels) over time, and provided evidence of the role that stress and self-efficacy may ultimately play in positive youth development (Damon 2004).

Fourthly, we set out to explore whether intra-individual change in the levels of perceived stress and self-efficacy interacts with the baseline levels of both. This investigation was guided by the assumption that within-person change in self-efficacy would moderate the adverse effects of baseline stress on life satisfaction (Hypothesis 6), but our models did 
not provide evidence for this. We also tested whether baseline levels of self-efficacy moderate the effects of within-person change in perceived stress on life satisfaction (Hypothesis 7), but the results also did not confirm this hypothesis. Finally, we analyzed whether life satisfaction is affected by an interplay between within-person change in self-efficacy and within-person change in stress, but findings indicated no such interaction effect.

Limitations of the present study should be noted. Social desirability bias could have affected the responses to the perceived stress scale items (Podsakoff et al. 2012). It is conceivable that this effect worked in two ways. Some respondents may have underreported their levels of stress, as they may have felt that reporting such feelings in the school context is socially undesirable. Others may have overstated their levels of stress as an expression of their psychological distance from this life domain. However, recent research shows that social desirability bias only minimally influences measures of life satisfaction in both adults and children (Holder 2012).

We should also note that we had a large sample and, consequently, a lot of power to identify even small effects as significant. Although the effects identified here were sizeable, it is important for future replication studies to take into account that statistical power will depend on sample size and on the size of the differences to be detected.

Another limitation is the potential confounding of the effects of baseline levels of stress and self-efficacy with change in the levels of stress and self-efficacy. Statistically, we separated these effects by applying a multilevel modeling framework, where baseline effects are at level two and change effects at level one. However, some of the crosslevel interactions, for example the interaction between baseline stress and change in self-efficacy, may be associated with inflated standard errors. Yet there are no reasons to assume that the parameter estimations of the cross-level interactions are not consistent. Our estimations show rather small, insignificant effects. Even if those effects were significant, they would not change the main relations between our key variables as their effect sizes are far greater. Connected to this, we are not aware of any research indicating that individuals with higher levels of baseline stress tend to show greater variation in self-efficacy across time.

Finally, although growth curve models allow us to analyze individual differences in life satisfaction trajectories over time and how life satisfaction is associated with our research variables, these models cannot determine causal direction. Hence, the effects reported in this article refer only to associations between variables and do not have a causal interpretation.

Our findings have implications for future research. They suggest not only that baseline stress and self-efficacy were related to young people's life satisfaction, but so too were intra-individual changes in stress and self-efficacy over time. However, it is unclear whether this is specific to young people or can be generalized to adults at different stages of the life-course. For instance, there is evidence that adults' temperament dispositions, such as extraversion and neuroticism (DeNeve and Cooper 1998; Herringer 1998), as well as adults' self-efficacy beliefs (Caprara and Steca 2005), are associated with their life satisfaction levels. However, there is conflicting evidence on the stability of adults' life satisfaction over extended periods of time. Some researchers claimed that adults' life satisfaction is a dynamic process characterized by substantial intra-individual variation (Heller et al. 2006), whereas others argued that adults' appraisals of their life satisfaction are relatively stable over time (Schimmack et al. 2009). Although it has been shown that major life events such as repeated or long-term unemployment, the onset of disability, or the loss of a partner can change life satisfaction in both the short and long term (Lucas et al. 2004; Luhmann et al. 2012), we do not know exactly at which points changes in adults' levels of stress and self-efficacy bring about significant alterations in life satisfaction (Chamberlain and Zika 1990). Future research should also investigate the impact of baseline stress on young people's life satisfaction. Although there has been an interest in the role minor stressors (such as daily hassles, social conflicts, or poor exam performance) play in life satisfaction (Ash and Huebner 2001; McCullough et al. 2000), much less is known on the impact of baseline stress on young people's life satisfaction (McNamara 2000).

Our findings also have implications for practice. Even though young people's life satisfaction was sensitive to perceived stress in education, self-efficacy seemed to buffer some of the negative effects of perceived stress on life satisfaction. Research shows that self-efficacy is a malleable resource, and therefore individuals can be enabled to strengthen their self-efficacy (Gist and Mitchell 1992; Schwoerer et al. 2005). Individuals who consider themselves worthy and capable of coping with life's demands feel happier and more in control of their life, and thus evaluate their life more favorably (Judge et al. 1998). Ultimately helping young people to enhance their selfefficacy, for instance through youth empowerment programs and psychological interventions at school, may not only have a strong impact on individual-level well-being, but also on public health levels more generally (Bandura 2004).

\section{Conclusion}

This study aimed to advance our understanding of whether, and to what extent, perceived stress and self-efficacy shape young people's life satisfaction. We found that baseline 
levels of stress and self-efficacy, as well as within-person change in perceived stress and self-efficacy, were associated with life satisfaction. Baseline stress and self-efficacy interacted in that high levels of baseline self-efficacy mitigated the negative effects of baseline stress on life satisfaction. This is an important finding, as it suggests that selfefficacy may act as a stress-buffering resource. Young people with low levels of self-efficacy may be unable to cope with perceived stress in the school environment, which increases the likelihood of leaving post-compulsory education early (Eicher et al. 2014). The corresponding nonpossession of a post-compulsory credential is associated with bleak prospects in the labor market for many young people in Western countries. Devoid of means to gain economic independence, these young people will struggle in the complex process of adulthood transition and experience severe restrictions in their life chances, as well as longterm consequences for their future career trajectories (Cockx and Picchio 2013), all of which will negatively affect their life satisfaction. Given these potentially serious consequences, the perception of stress in the domain of schooling needs to be better understood. Moreover, it will be valuable for practitioners to know how self-efficacy interventions may address stress, helping to counteract the adverse effects perceived stress has on young people's future life chances.

Acknowledgments The research drew on data collected by the Transition from Education to Employment project (TREE). The Swiss youth panel study TREE has been running since 2000 and has since been funded by the Swiss National Science Foundation, the University of Basel, the Swiss Federal Office of Statistics, the Federal Office of Professional Education and Technology, and the cantons of Berne, Geneva and Ticino. Both authors would like to thank Anita C. Keller and Karoline Lohse for comments on previous versions of this manuscript and Samuel Ian Quigg for proofreading the manuscript.

Funding This research received no grant from any funding agency in the public, commercial, or not-for-profit sectors.

Authors' Contributions KB conceived of the study, guided the data analysis and interpretation, and coordinated and drafted the manuscript. RS participated in and extended the data analysis and interpretation and drafted the manuscript. Both authors read and approved the final manuscript.

\section{Compliance with Ethical Standards}

Conflict of Interest The authors declare that they have no competing interests.

Ethical Approval All data analyses in the present study were performed on anonymous and secondary data. All procedures performed in the original study, which involved human participants, were in accordance with the ethical standards of the institutions involved in data collection.

Informed Consent This article does not contain any studies with human participants or animals performed by any of the authors.

\section{References}

Adams, R., Wu, M. (Eds.) (2002). PISA 2000 technical report. Paris: OECD/PISA.

Ainscough, L., Foulis, E., Colthorpe, K., Zimbardi, K., RobertsonDean, M., Chunduri, P., \& Lluka, L. (2016). Changes in biology self-efficacy during a first-year university course. CBE-Life Sciences Education, 15, 1-12.

Antaramian, S. P., Huebner, E. S., \& Valois, R. F. (2008). Adolescent life satisfaction. Applied Psychology, 57, 112-126.

Ash, C., \& Huebner, E. S. (2001). Environmental events and life satisfaction reports of adolescents: A test of cognitive mediation. School Psychology International, 22(3), 320-336.

Baird, B. M., Lucas, R. E., \& Donnellan, M. B. (2010). Life satisfaction across the lifespan: Findings from two nationally representative panel studies. Social Indicators Research, 99(2), 183-203.

Bandura, A. (1997). Self-efficacy: The exercise of control. New York: W.H. Freeman and Company.

Bandura, A. (2004). Health promotion by social cognitive means. Health Education \& Behavior, 31(2), 143-164.

Bandura, A. (2006). Toward a psychology of human agency. Perspectives on Psychological Science, 1(2), 164-180.

Baumeister, R. F., Bratslavsky, E., Finkenauer, C., \& Vohs, K. D. (2001). Bad is stronger than good. Review of General Psychology, 5(4), 323-370.

Bergman, M. M., Hupka-Brunner, S., Keller, A., Meyer, T., \& Stalder, B. E. (2011). Transitionen im Jugendalter: Ergebnisse der schweizer länggschnittstudie TREE. Zürich: Seismo.

Bradley, R. H., \& Corwyn, R. F. (2004). Life satisfaction among European American, African American, Chinese American, Mexican American, and Dominican American adolescents. International Journal of Behavioral Development, 28(5), 385-400.

Buchanan, C., \& Hughes, J. L. (2011). Storm and stress. In R. J. R. Levesque (Ed.), Encyclopedia of adolescence (pp. 2877-2885). New York: Springer.

Burger, K., \& Walk, M. (2016). Can children break the cycle of disadvantage? Structure and agency in the transmission of education across generations. Social Psychology of Education. doi:10.1007/ s11218-016-9361-y.

Caprara, G. V., Pastorelli, C., Regalia, C., Scabini, E., \& Bandura, A. (2005). Impact of adolescents' filial self-efficacy on quality of family functioning and satisfaction. Journal of Research on Adolescence, 15(1), 71-97.

Caprara, G. V., \& Steca, P. (2005). Self-efficacy beliefs as determinants of prosocial behavior conducive to life satisfaction across ages. Journal of Social and Clinical Psychology, 24(2), 191-217.

Caprara, G. V., Vecchione, M., Alessandri, G., Gerbino, M., \& Barbaranelli, C. (2011). The contribution of personality traits and self-efficacy beliefs to academic achievement: A longitudinal study. British Journal of Educational Psychology, 81(1), 78-96.

Chamberlain, K., \& Zika, S. (1990). The minor events approach to stress: Support for the use of daily hassles. British Journal of Psychology, 81(4), 469-481.

Chang, E. C. (1998). Does dispositional optimism moderate the relation between perceived stress and psychological well-being? A preliminary investigation. Personality and Individual Differences, 25(2), 233-240.

Cockx, B., \& Picchio, M. (2013). Scarring effects of remaining unemployed for long-term unemployed school-leavers. Journal of the Royal Statistical Society: Series A, 176(4), 951-980.

Compas, B. E., Connor-Smith, J. K., Saltzman, H., Thomsen, A. H., \& Wadsworth, M. E. (2001). Coping with stress during childhood and adolescence: Problems, progress, and potential in theory and research. Psychological Bulletin, 127(1), 87-127. 
Curran, P. J., Obeidat, K., \& Losardo, D. (2010). Twelve frequently asked questions about growth curve modeling. Journal of Cognition and Development, 11(2), 121-136.

Damon, W. (2004). What is positive youth development? The ANNALS of the American Academy of Political and Social Science, 591(1), 13-24.

Dempster, A. P., Laird, N. M., \& Rubin, D. B. (1977). Maximum likelihood from incomplete data via the EM algorithm. Journal of the Royal Statistical Society: Series B, 39(1), 1-38.

DeNeve, K. M., \& Cooper, H. (1998). The happy personality: A metaanalysis of 137 personality traits and subjective well-being. Psychological Bulletin, 124(2), 197-229.

Diener, E. (2009). The science of well-being: The collected works of Ed Diener. New York: Springer.

Diener, E., \& Chan, M. Y. (2011). Happy people live longer: Subjective well-being contributes to health and longevity. Applied Psychology: Health and Well-Being, 3(1), 1-43.

Do, C. B., \& Batzoglou, S. (2008). What is the expectation maximization algorithm? Nature Biotechnology, 26(8), 897-899.

Eicher, V., Staerklé, C., \& Clémence, A. (2014). I want to quit education: A longitudinal study of stress and optimism as predictors of school dropout intention. Journal of Adolescence, 37(7), 1021-1030.

Ganzeboom, H. B. G., De Graaf, P. M., \& Treiman, D. J. (1992). A standard international socio-economic index of occupational status. Social Science Research, 21(1), 1-56.

Gilman, R., \& Huebner, S. (2003). A review of life satisfaction research with children and adolescents. School Psychology Quarterly, 18(2), 192-205.

Gist, M. E., \& Mitchell, T. R. (1992). Self-efficacy: A theoretical analysis of its determinants and malleability. Academy of Management Review, 17(2), 183-211.

Grant, K. E., Compas, B. E., Thurm, A. E., McMahon, S. D., Gipson, P. Y., Campbell, A. J., et al. (2006). Stressors and child and adolescent psychopathology: Evidence of moderating and mediating effects. Clinical Psychology Review, 26(3), 257-283.

Grob, A., Lüthi, R., Kaiser, F. G., Flammer, A., Mackinnon, A., \& Wearing, A. J. (1991). Berner Fragebogen zum Wohlbefinden Jugendlicher (BFW). Diagnostica, 37(1), 66-75.

Hamarat, E., Thompson, D., Zabrucky, K. M., Steele, D., Matheny, K. B., \& Aysan, F. (2001). Perceived stress and coping resource availability as predictors of life satisfaction in young, middle-aged, and older adults. Experimental Aging Research, 27(2), 181-196.

Hampel, P., \& Petermann, F. (2006). Perceived stress, coping, and adjustment in adolescents. Journal of Adolescent Health, 38(4), 409-415.

Heller, D., Watson, D., \& Ilies, R. (2006). The dynamic process of life satisfaction. Journal of Personality, 74(5), 1421-1450.

Herringer, L. G. (1998). Facets of extraversion related to life satisfaction. Personality and Individual Differences, 24(5), 731-733.

Hobfoll, S. E. (2002). Social and psychological resources and adaptation. Review of General Psychology, 6(4), 307-324.

Holder, M. D. (2012). Happiness in children. Dordrecht: Springer.

Huber, P. J. (1967). The behavior of maximum likelihood estimates under nonstandard conditions. In Proceedings of the Fifth Berkeley Symposium on Mathematical Statistics and Probability (Vol. 1, pp. 221-233).

Huebner, E. S., Gilman, R., \& Ma, C. (2012). Perceived quality of life of children and youth. In K. C. Land, A. C. Michalos, \& M. J. Sirgy (Eds.), Handbook of social indicators and quality of life research (pp. 355-372). Dordrecht: Springer.

Huebner, E. S., Suldo, S. M., \& Gilman, R. (2006). Life satisfaction. In G. G. Bear, \& K. M. Minke (Eds.), Children's needs III: Development, prevention, and intervention ( $\mathrm{pp}$. 357-368). Washington, DC: National Association of School Psychologists.
Jerusalem, M., \& Mittag, W. (1995). Self-efficacy in stressful life transitions. In A. Bandura (Ed.), Self-efficacy in changing societies (pp. 177-201). New York: Cambridge University Press.

Judge, T. A., Locke, E. A., Durham, C. C., \& Kluger, A. N. (1998). Dispositional effects on job and life satisfaction: The role of core evaluations. Journal of Applied Psychology, 83(1), 17-34.

Keller, A. C., Samuel, R., Semmer, N. K., Bergman, M. M. (Eds.) (2014). Psychological, educational and sociological perspectives on success and well-being in career development. New York: Springer.

Keyes, C. L. M., \& Waterman, M. B. (2003). Dimensions of wellbeing and mental health in adulthood. In M. H. Bornstein, L. Davidson, C. L. M. Keyes, \& K. A. Moore (Eds.), Well-being: Positive development across the life course (pp. 477-497). Mahwah, NJ: Lawrence Erlbaum Associates Publishers.

Lazarus, R. S., \& Folkman, S. (1984). Stress, appraisal, and coping. New York: Springer.

Lerner, R. M., \& Galambos, N. L. (1998). Adolescent development: Challenges and opportunities for research, programs, and policies. Annual Review of Psychology, 49(1), 413-446.

Lewis, A. D., Huebner, E. S., Malone, P. S., \& Valois, R. F. (2011). Life satisfaction and student engagement in adolescents. Journal of Youth and Adolescence, 40(3), 249-262.

Lucas, R. E., Clark, A. E., Georgellis, Y., \& Diener, E. (2004). Unemployment alters the set point for life satisfaction. Psychological Science, 15(1), 8-13.

Lucas, R. E., \& Donnellan, M. B. (2007). How stable is happiness? Using the STARTS model to estimate the stability of life satisfaction. Journal of Research in Personality, 41(5), 1091-1098.

Luhmann, M., Hofmann, W., Eid, M., \& Lucas, R. E. (2012). Subjective well-being and adaptation to life events: A meta-analysis on differences between cognitive and affective well-being. Journal of Personality and Social Psychology, 102(3), 592-615.

Luhmann, M., Lucas, R. E., Eid, M., \& Diener, E. (2013). The prospective effect of life satisfaction on life events. Social Psychological and Personality Science, 4(1), 39-45.

Luszczynska, A., Gutiérrez-Doña, B., \& Schwarzer, R. (2005). General self-efficacy in various domains of human functioning: Evidence from five countries. International Journal of Psychology, 40(2), 80-89.

Lyubomirsky, S., King, L., \& Diener, E. (2005). The benefits of frequent positive affect: Does happiness lead to success? Psychological Bulletin, 131(6), 803-855.

McCullough, G., Huebner, E. S., \& Laughlin, J. E. (2000). Life events, self-concept, and adolescents' positive subjective well-being. Psychology in the Schools, 37(3), 281-290.

McKnight, C. G., Huebner, E. S., \& Suldo, S. (2002). Relationships among stressful life events, temperament, problem behavior, and global life satisfaction in adolescents. Psychology in the Schools, 39(6), 677-687.

McNamara, S. (2000). Stress in young people: What's new and what to do. London, New York: Continuum.

Moksnes, U. K., Løhre, A., Lillefjell, M., Byrne, D. G., \& Haugan, G. (2014). The association between school stress, life satisfaction and depressive symptoms in adolescents: Life satisfaction as a potential mediator. Social Indicators Research, 125(1), 339-357.

Mroczek, D. K., \& Almeida, D. M. (2004). The effect of daily stress, personality, and age on daily negative affect. Journal of Personality, 72(2), 355-378.

Muthén, B., \& Shedden, K. (1999). Finite mixture modeling with mixture outcomes using the EM algorithm. Biometrics, 55(2), 463-469.

Nie, Y., Lau, S., \& Liau, A. K. (2011). Role of academic self-efficacy in moderating the relation between task importance and test anxiety. Learning and Individual Differences, 21(6), 736-741. 
Oberle, E., Schonert-Reichl, K. A., \& Zumbo, B. D. (2011). Life satisfaction in early adolescence: Personal, neighborhood, school, family, and peer influences. Journal of Youth and Adolescence, 40(7), 889-901.

O'Sullivan, G. (2010). The relationship between hope, eustress, selfefficacy, and life satisfaction among undergraduates. Social Indicators Research, 101(1), 155-172.

Ouweneel, E., Schaufeli, W. B., \& Le Blanc, P. M. (2013). Believe, and you will achieve: Changes over time in self-efficacy, engagement, and performance. Applied Psychology: Health and Well-Being, 5(2), 225-247.

Pajares, F., \& Urdan, T. C. (2006). Self-efficacy beliefs of adolescents. Charlotte: IAP

Park, N. (2005). Life satisfaction among Korean children and youth. A developmental perspective. School Psychology International, 26 (2), 209-223.

Peng, A. C., Schaubroeck, J. M., \& Xie, J. L. (2015). When confidence comes and goes: How variation in self-efficacy moderates stressor-strain relationships. Journal of Occupational Health Psychology, 20(3), 359-376.

Persike, M., \& Seiffge-Krenke, I. (2012). Competence in coping with stress in adolescents from three regions of the world. Journal of Youth and Adolescence, 41(7), 863-879.

Peterson, C., Seligman, M. E., Yurko, K. H., Martin, L. R., \& Friedman, H. S. (1998). Catastrophizing and untimely death. Psychological Science, 9(2), 127-130.

Pinquart, M., Juang, L. P., \& Silbereisen, R. K. (2003). Self-efficacy and successful school-to-work transition: A longitudinal study. Journal of Vocational Behavior, 63(3), 329-346.

Podsakoff, P. M., MacKenzie, S. B., \& Podsakoff, N. P. (2012). Sources of method bias in social science research and recommendations on how to control it. Annual Review of Psychology, 63(1), 539-569.

Proctor, C., Linley, P., \& Maltby, J. (2009). Youth life satisfaction: A review of the literature. Journal of Happiness Studies, 10(5), 583-630.

Prümper, J., Hartmannsgruber, K., \& Frese, M. (1995). KurzFragebogen zur Arbeitsanalyse (KFZA). Zeitschrift für Arbeitsund Organisationspsychologie, 39(3), 125-131.

Raudenbush, S. W., \& Bryk, A. S. (2002). Hierarchical linear models: Applications and data analysis methods. Thousand Oaks: Sage. (Vol. 1).

Rogers, W. (1994). Regression standard errors in clustered samples. Stata Technical Bulletin, 3(13), 19-23.

Rosenberg, E. L. (1998). Levels of analysis and the organization of affect. Review of General Psychology, 2(3), 247-270.

Salmela-Aro, K., \& Tynkkynen, L. (2010). Trajectories of life satisfaction across the transition to post-compulsory education: Do adolescents follow different pathways? Journal of Youth and Adolescence, 39(8), 870-881.

Samuel, R., Bergman, M. M., \& Hupka-Brunner, S. (2013). The interplay between educational achievement, occupational success, and well-being. Social Indicators Research, 111(1), 75-96.

Sánchez-Álvarez, N., Extremera, N., \& Fernández-Berrocal, P. (2015). Maintaining life satisfaction in adolescence: Affective mediators of the influence of perceived emotional intelligence on overall life satisfaction judgments in a two-year longitudinal study. Frontiers in Psychology, doi:10.3389/fpsyg.2015.01892.

Schafer, J. L., \& Graham, J. W. (2002). Missing data: Our view of the state of the art. Psychological Methods, 7(2), 147-177.

Schimmack, U., Diener, E., \& Oishi, S. (2009). Life-satisfaction is a momentary judgment and a stable personality characteristic: The use of chronically accessible and stable sources. In P. E. Diener (Ed.), Assessing well-being (pp. 181-212). Dordrecht: Springer.

Schmeelk-Cone, K. H., \& Zimmerman, M. A. (2003). A longitudinal analysis of stress in African-American youth: Predictors and outcomes of stress trajectories. Journal of Youth and Adolescence, 32(6), 419-430.

Scholz, U., Gutiérrez Doña, B., Sud, S., \& Schwarzer, R. (2002). Is general self-efficacy a universal construct? European Journal of Psychological Assessment, 18(3), 242-251.

Schwarzer, R. (2000). General perceived self-efficacy in 14 cultures. Berlin: Freie Universität Berlin. http://userpage.fu-berlin.de/ health/world14.htm. Accessed 18 Aug 2016.

Schwarzer, R., \& Jerusalem, M. (1999). Skalen zur Erfassung von Lehrer- und Schülermerkmalen. Dokumentation der psychometrischen Verfahren im Rahmen der Wissenschaftlichen Begleitung des Modellversuchs Selbstwirksame Schulen. Berlin: Freie Universität Berlin und Humboldt-Universität zu Berlin.

Schwarzer, R., Mueller, J., \& Greenglass, E. (1999). Assessment of perceived general self-efficacy on the internet: Data collection in cyberspace. Anxiety, Stress, \& Coping, 12(2), 145-161.

Schwoerer, C. E., May, D. R., Hollensbe, E. C., \& Mencl, J. (2005). General and specific self-efficacy in the context of a training intervention to enhance performance expectancy. Human Resource Development Quarterly, 16(1), 111-129.

Sitzmann, T., \& Yeo, G. (2013). A meta-analytic investigation of the within-person self-efficacy domain: Is self-efficacy a product of past performance or a driver of future performance? Personnel Psychology, 66(3), 531-568.

Snijders, T. A., \& Bosker, R. J. (2012). Multilevel analysis: An introduction to basic and advanced multilevel modeling. Los Angeles, CA: Sage.

Suldo, S. M., \& Huebner, E. S. (2006). Is extremely high life satisfaction during adolescence advantageous? Social Indicators Research, 78(2), 179-203.

Suldo, S. M., Riley, K. N., \& Shaffer, E. J. (2006). Academic correlates of children and adolescents' life satisfaction. School Psychology International, 27(5), 567-582.

Tolan, P. H., \& Larsen, R. (2014). Trajectories of life satisfaction during middle school: Relations to developmental-ecological microsystems and student functioning. Journal of Research on Adolescence, 24(3), 497-511.

TREE. (2013). TREE project documentation 2000-2012. Basel: TREE. Watson, D. (1990). On the dispositional nature of stress measures: Stable and nonspecific influences on self-reported hassles. Psychological Inquiry, 1(1), 34-37.

Yeo, G. B., \& Neal, A. (2006). An examination of the dynamic relationship between self-efficacy and performance across levels of analysis and levels of specificity. Journal of Applied Psychology, 91(5), 1088-1101. 